Article

\title{
Assessment of a Coastal Offshore Wind Climate by Means of Mesoscale Model Simulations Considering High-Resolution Land Use and Sea Surface Temperature Data Sets
}

\author{
Yuka Kikuchi ${ }^{1}$, Masato Fukushima ${ }^{2}$ and Takeshi Ishihara ${ }^{1, *}$ \\ 1 Department of Civil Engineering, The University of Tokyo, Tokyo 113-8656, Japan; \\ kikuchi@bridge.t.u-tokyo.ac.jp \\ 2 Electric Power Development Co., Ltd., Tokyo 104-8165, Japan; masato_fukushima@jpower.co.jp \\ * Correspondence: ishihara@bridge.t.u-tokyo.ac.jp
}

Received: 28 February 2020; Accepted: 11 April 2020; Published: 13 April 2020

check for updates

\begin{abstract}
In this study, offshore wind climate assessments are carried out by using mesoscale model Weather Research and Forecasting (WRF) and validated by measurement at a demonstration site located $3.1 \mathrm{~km}$ offshore of Choshi. An optimal nudging method is investigated by using offshore and meteorological observations. The land-use datasets are then created from a higher-resolution land-use data by using a maximum area sampling scheme according to the horizontal resolution of the mesoscale model. Finally, the sea surface temperature datasets are corrected by observation data. It is found that the relative error of annual wind speed is reduced from $7.3 \%$ to $2.2 \%$ and the correlation coefficient between predicted and measured wind speed is improved from 0.80 to 0.84 by considering the effects of land-use and sea surface temperature.
\end{abstract}

Keywords: mesoscale model; land-use data; sea surface temperature; nudging; wind speed

\section{Introduction}

Offshore wind energy has been rapidly growing as a renewable energy resource worldwide. Offshore wind climate assessment is important to evaluate a prospective offshore wind project. The meteorological masts [1-5] and floating lidar [6,7] have been developed to observe the precise wind profile at the specific place. Meanwhile, mesoscale modeling is broadly used to evaluate the spatially distributed wind profile. The combination of the meteorological mast or floating lidar with mesoscale modeling enables a highly accurate prediction, which is especially important at a non-uniform offshore wind climate such as a coastal region. Various studies have been conducted using the Weather Research and Forecasting (WRF) mesoscale model [8] developed by the National Center for Atmospheric Research. Berge et al. (2009) [9] showed the relative error of annual average wind speed was $1 \%$ between the WRF simulation and observations in FINO1 [1] at the height of $100 \mathrm{~m}$ above the sea surface. Hahmann et al. (2015) [10] indicated the relative errors of annual average wind speed were about $-4 \%$ to $3 \%$ between WRF simulations with various parameter settings and observations at FINO1 at the height of $90 \mathrm{~m}$ and FINO2 [2] at the height of $92 \mathrm{~m}$.

In Japan, the New Energy and Industrial Technology Development Organization had initiated the national demonstration project for a fixed-bottom offshore wind plant at Choshi, Chiba prefecture facing the Pacific Ocean since 2012 [5]. This offshore wind plant is located $3.1 \mathrm{~km}$ far from the coast and the water depth is about $11 \mathrm{~m}$, consisting of one 2.4 MW Mitsubishi Heavy Industry wind turbine and one offshore meteorological mast. At the meteorological mast, wind speed and direction are observed at eight altitudes from the height of $20 \mathrm{~m}$ to $90 \mathrm{~m}$ to obtain the vertical wind profile. It is important 
to investigate the effects of land-use and sea surface temperature on the wind climate assessment by using the mesoscale modeling technique for offshore projects in Japan, since the most of the promised areas for fixed-bottom offshore wind farms are located in the coastal regions about $3-5 \mathrm{~km}$ far from the coast. Fukushima and Ishihara [11] showed that the relative error was 7\% between WRF simulations and the observations with the same option as used by Berge et al. [9] and the observation in the mast at Choshi. The reason for the larger relative error is suggested that Choshi is located in Japan's coastal region, while FINO 1 and FINO2 are located $45 \mathrm{~km}$ and $33 \mathrm{~km}$ offshore.

The prediction in the coastal region $3.1 \mathrm{~km}$ far from the coast was challenging. The resolution of the innermost domain was set as $2 \mathrm{~km}$ based on the previous study by Ishihara et al. [12], where the sensitivity of grid resolution with $2 \mathrm{~km}, 666 \mathrm{~m}$, and $222 \mathrm{~m}$ was conducted at Choshi with the same turbulence model and parameters. They mentioned that the predicted monthly average wind speed was almost the same between $2 \mathrm{~km}$ and $222 \mathrm{~m}$ resolution, which indicates that the larger relative error does not come from the grid resolution but may come from the land-use and sea surface temperature datasets. The complex land-use around Choshi has a stronger effect on the offshore climate. The presence of the current Kuroshio and the inflow of the Tone River also results in a non-uniform distribution of sea surface temperature (SST) along the coastline of this site.

The sensitivity of WRF to land-use datasets has been examined. Lopez-Espinoza et al. [13], Cheng et al. [14], and Li et al. [15] pointed out that the increased urbanization produces increased daytime and nighttime temperatures. Li et al. [15] and Kamal et al. [16] showed that land-use also affects wind speeds and circulation patterns as the roughness length increases. Mallard et al. (2018) [17] investigated the effect of land-use on wind resource prediction in the United States by comparing 1-km standard United States Geological Survey (USGS) data and $30 \mathrm{~m}$ resolution National Land Cover Dataset (NLCD). The New European Wind Atlas [18] uses $100 \mathrm{~m}$ resolution land-use data instead of the standard USGS data. The effects of land-use data on a coastal offshore wind climate need to be clarified.

Mallard et al. [17] suggested that when finer land-use data is applied to the WRF, the interpolation method for land-use data is worth consideration. For datasets that provide one dominant land-use category per pixel, the nearest neighbor method is preferred and is set as the default, otherwise, the bilinear interpolation or averaging methods are preferred when the source dataset provides fractional values of land-use within each pixel for each category as is the case with USGS and NLCD datasets. Yoshie and Miura [18] proposed the maximum area scheme because the parameter in this method clearly corresponds to each land-use category compared with the bilinear interpolation or averaging methods and the precision increases with the increase of grid resolution.

Shimada et al. (2014) [19] pointed out that the use of accurate SST in the mesoscale model is a key factor. The use of a high-resolution SST from the Operational Sea Surface Temperature and Sea Ice Analysis (OSTIA) dataset [20] yields a better accuracy of the simulated winds compared with the use of a low-resolution SST from the National Centers for Environmental Prediction Final analysis (FNL) dataset [21]. The New European Wind Atlas (2019) [22] also investigated the effect of SST on wind profiles by using OSTIA. The OSTIA dataset is obtained from satellite observation and an innovative bias correction scheme based on the use of ENVISAT AATSR measurements and in situ SST measurements is a fundamental component of the analysis system. However, OSTIA still does not reflect the local effect such as the river inflow. The correction method of sea surface database with observation to reflect the local phenomena needs to be investigated.

Stauffer et al. $[23,24]$ showed that the four-dimensional data assimilation (FDDA) also known as nudging successfully reduced larger-scale phase and amplitude errors while the model realistically simulated mesoscale features which were either poorly defined or absent in the model simulations without FDDA. Vincent and Hahmann [22,25] investigated the effect of nudging and indicated that nudging an outer domain is an appropriate configuration for wind-resource modeling. Fukushima and Ishihara [11] and Misaki et al. [26] conducted the nudging by applying the grid nudging to full levels in the outer domain, and to the levels above the top of the planetary boundary layer in the inner 
domain. The nudging needs to be optimized before investigating the effect of land-use and sea surface temperature data. Various studies about the nudging to observations have been examined to obtain the accurate wind resource, but the nudging to the analyses data is required for offshore wind resource assessment without the local observation data.

In this study, wind climate assessment is conducted by using the mesoscale meteorological model WRF and the predicted wind profile is compared with measurements obtained at Choshi met mast. In Section 2, the numerical model and observation data are described in detail. In Section 3, the optimal nudging method is investigated by using offshore and meteorological observations. The land-use datasets are then created from a higher-resolution land-use data by using the maximum area sampling scheme according to the horizontal resolution of the mesoscale model and the effect of land use database is investigated. The correction method of sea surface database with observation is proposed and the effect of sea surface temperature is investigated. Finally, the predicted annual and seasonal average wind speeds are evaluated. The conclusions are summarized in Section 4.

\section{Numerical Model and Field Measurement}

In this section, the numerical model is described in Section 2.1 and the field measurement is explained in Section 2.2.

\subsection{Numerical Model}

An advanced mesoscale model WRF (Weather Research and Forecasting) Version 3.4 [8] is used to perform the simulations for a period of one year from 1st February 2013 to 31th January 2014. The simulations are conducted with a spin-up period of one month. The computational domain and the model configuration used in the WRF simulations are shown in Figure 1 and Table 1. Two nested domains are set around the offshore meteorological mast at Choshi. The outer domain has $18 \mathrm{~km}$ resolution and the second domain has a $6 \mathrm{~km}$ resolution, while the inner domain has a $2 \mathrm{~km}$ resolution. The minimum resolution is set as $2 \mathrm{~km}$ because Ishihara et al. [12] clarified that a resolution of less than $2 \mathrm{~km}$ does not affect the prediction accuracy as shown in Section 1. Forty-five layers are employed in the vertical direction, of which 11 layers are set below $200 \mathrm{~m}$ at the same heights of the Doppler lidar measurement described in Section 2.2. FiNal operational global analysis data provided by NCEP (NCEP FNL) data [21] are used for the initial and lateral boundary conditions. As a default setting, the United States Geological Survey (USGS) data [27] are used for terrain and land-use data and FNL data is used for SST data.

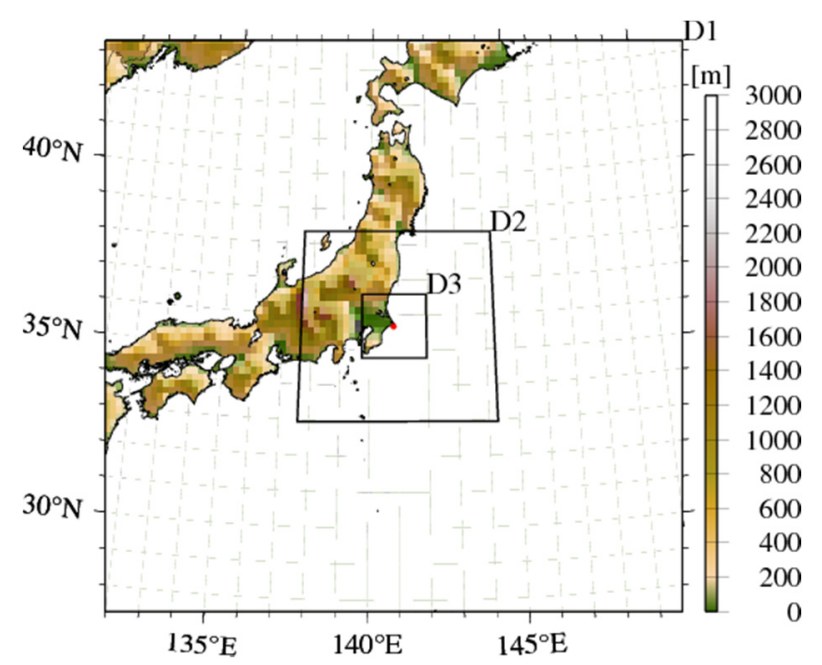

Figure 1. Domain configurations for Weather Research and Forecasting (WRF) simulations. 
Table 1. Description of the mesoscale model and computational conditions.

\begin{tabular}{|c|c|c|c|}
\hline & Domain 1 & Domain 2 & Domain 3 \\
\hline Simulation period & \multicolumn{3}{|c|}{ February 2013-January 2014} \\
\hline Domain & $\begin{array}{c}133^{\circ}-149^{\circ} \mathrm{E} \\
28.0^{\circ}-44.0^{\circ} \mathrm{N}\end{array}$ & $\begin{array}{c}138.5^{\circ}-142.5^{\circ} \mathrm{E} \\
33.5^{\circ}-37.5^{\circ} \mathrm{N}\end{array}$ & $\begin{array}{c}139.7^{\circ}-141.3^{\circ} \mathrm{E}, \\
34.7^{\circ}-36.3^{\circ} \mathrm{N}\end{array}$ \\
\hline Horizontal resolution & $\begin{array}{c}18 \mathrm{~km} \\
(100 \times 100 \text { grids })\end{array}$ & $\begin{array}{c}6 \mathrm{~km} \\
(100 \times 100 \text { grids })\end{array}$ & $\begin{array}{c}2 \mathrm{~km} \\
(100 \times 100 \text { grids })\end{array}$ \\
\hline Vertical resolution & \multicolumn{3}{|c|}{45 levels (Surface to $50 \mathrm{hPa}$ ) } \\
\hline Time step & $72 \mathrm{sec}$. & $24 \mathrm{sec}$. & $8 \mathrm{sec}$. \\
\hline Spin-up & \multicolumn{3}{|c|}{ One month } \\
\hline Boundary condition & \multicolumn{3}{|c|}{ NCEP-FNL $1^{\circ} \times 1^{\circ}$ 6-hourly } \\
\hline Physics option & \multicolumn{3}{|c|}{$\begin{array}{l}\text { Ferrier (new Eta) microphysics scheme } \\
\text { Rapid radiative transfer model } \\
\text { Dudhia scheme } \\
\text { Monin-Obukhov (Janjic Eta) scheme } \\
\text { Unified Noah land surface model } \\
\text { Mellor-Yamada-Janjic (Eta) TKE level } 2.5 \text { scheme } \\
\text { Betts-Miller-Janic scheme (Except for domain 3) }\end{array}$} \\
\hline Nudging & \multicolumn{3}{|c|}{ Described in Section 3.1} \\
\hline Land use & \multicolumn{3}{|c|}{ Described in Section 3.2} \\
\hline Sea surface temperature & \multicolumn{3}{|c|}{ Described in Section 3.3} \\
\hline
\end{tabular}

\subsection{Field Measurement}

The Choshi offshore meteorological mast has been operational since 2011 in the Pacific Ocean about $3.1 \mathrm{~km}$ east of the Chiba prefecture. The mast is located at $35^{\circ} 68^{\prime} 16^{\prime \prime} \mathrm{N}, 140^{\circ} 82^{\prime} 33^{\prime \prime} \mathrm{E}$ in the world geodetic system. The wind turbine is located about $285 \mathrm{~m}$ west of the offshore met mast. Figure 2 shows the configuration of the installed measurement equipment at the mast. The maximum height of measurement is $95 \mathrm{~m}$ above the lowest astronomical tide. Table 2 summarizes the specification of measurement equipment. Wind speeds are measured by cup anemometers, ultrasonic anemometers and a Doppler lidar and wind directions are measured by vane anemometers. Ultrasonic anemometer data at the direction of 101.25-135.8 degrees and 258.75-281.25 degrees are excluded, which are affected by the wake of the mast and the wind turbine, respectively. Doppler lidar data at the direction of 258.75-281.25 degrees are excluded, which are affected by the wake of the wind turbine. Figure 3 shows the frequency distributions of wind speed and wind rose at the height of $80 \mathrm{~m}$ measured by ultrasonic anemometer and Doppler lidar. The frequency distributions of wind speed and direction measured by ultrasonic anemometer and Doppler lidar agree well. The annual average wind speeds of the ultrasonic anemometer and Doppler lidar are both of $7.79 \mathrm{~m} / \mathrm{s}$.

Figure 4 shows the comparison of $10 \mathrm{~min}$ average wind speeds measured by the ultrasonic anemometer and those by the Doppler lidar. The bias and root mean square error (RMSE) are evaluated by Equations (1) and (2).

$$
\begin{gathered}
\text { bias }=\overline{u_{\text {lidar }}}-\overline{u_{\text {sonic }}} \\
\text { rmse }=\sqrt{\frac{1}{N} \sum_{i=1}^{N}\left(u_{\text {lidar }}-u_{\text {sonic }}\right)^{2}}
\end{gathered}
$$

where $u_{\text {lidar }}$ and $u_{\text {sonic }}$ is 10 min average wind speed measured by a Doppler lidar and an ultrasonic anemometer, respectively, the bar indicates the monthly average, and $N$ is the number of samples. The bias of wind speed measured by the ultrasonic anemometer and the Doppler lidar is small with $0.03 \mathrm{~m} / \mathrm{s}$ and the coefficient of the determination is high with 0.991 at the height of $80 \mathrm{~m}$. In this study, 10 min average wind speed by the Doppler lidar is used for validation of the mesoscale model. 
Table 2. Specification of the observations.

\begin{tabular}{ccc}
\hline Equipment & Height & Sampling Rate \\
\hline Cup anemometer & 8 heights $(20 \mathrm{~m}-90 \mathrm{~m}, 10 \mathrm{~m}$ interval $)$ & $4 \mathrm{~Hz}$ \\
Vane anemometer & 9 heights $(20-90 \mathrm{~m}, 10 \mathrm{~m}$ interval, $95 \mathrm{~m})$ & $4 \mathrm{~Hz}$ \\
Ultrasonic anemometer & 3 heights $(40,60,80 \mathrm{~m})$ & $20 \mathrm{~Hz}$ \\
Doppler lidar & 8 heights $(60-200 \mathrm{~m}, 20 \mathrm{~m}$ interval) & $4 \mathrm{~Hz}$ \\
Water temperature meter & 3 heights (T.P. $0 \mathrm{~m},-1 \mathrm{~m},-2 \mathrm{~m})$ & $4 \mathrm{~Hz}$ \\
Barometer & 1 height (Platform) & $4 \mathrm{~Hz}$ \\
Thermo-hygrometer & 2 heights $(30 \mathrm{~m}, 80 \mathrm{~m})$ & $4 \mathrm{~Hz}$ \\
Differential temperature meter & 4 heights $(30-90 \mathrm{~m}, 20 \mathrm{~m}$ interval $)$ & $4 \mathrm{~Hz}$ \\
\hline
\end{tabular}

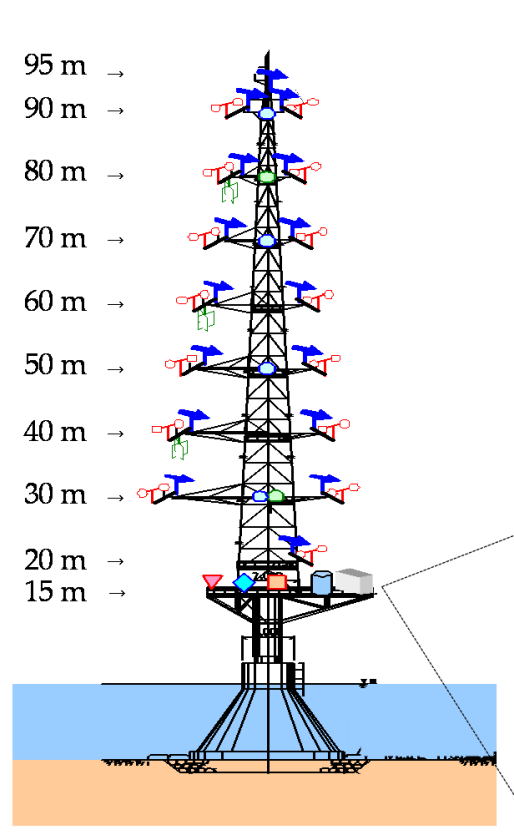

\begin{tabular}{|c|l|}
\hline & Measurement installment \\
\hline$T$ & Cup anemometer \\
\hline$T$ & Vane anemometer \\
\hline$\square$ & Ultrasonic anemometer \\
\hline$\square$ & Doppler lidar \\
\hline$\square$ & Barometer \\
\hline$\bigcirc$ & Thermo-hygrometer \\
\hline$\square$ & Differential temperature meter \\
\hline$\square$ & Rain gauge \\
\hline$\triangleright$ & Visibility meter \\
\hline$\nabla$ & Infrared radiation thermometer \\
\hline$\square$ & Water temperature meter \\
\hline
\end{tabular}

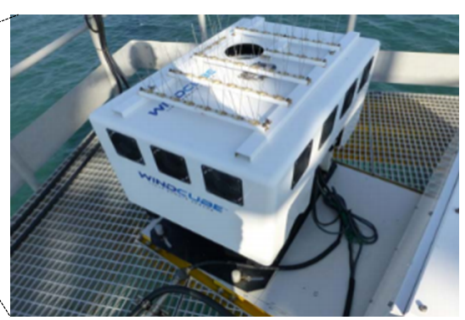

Figure 2. Installed measurement equipment.

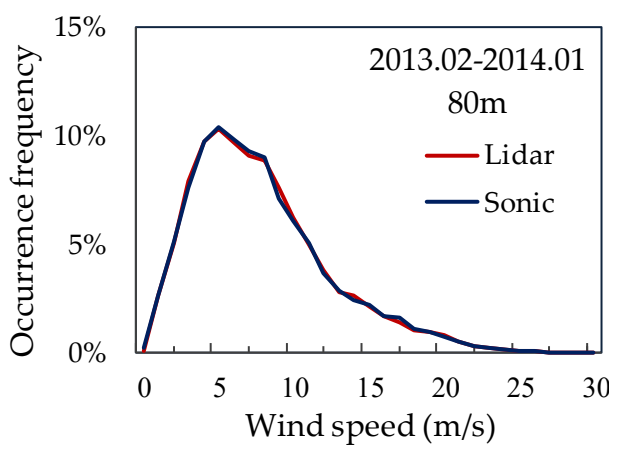

(a)

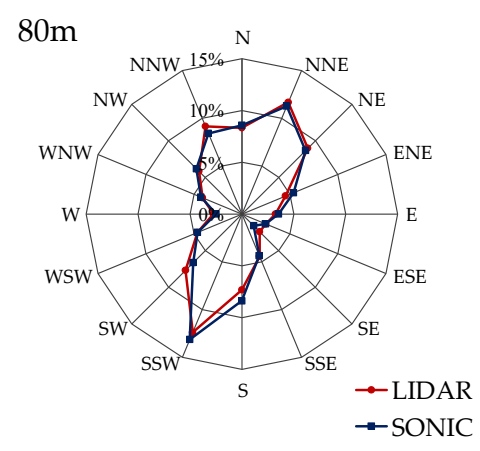

(b)

Figure 3. (a) Frequency distributions of wind speed at the hub height and (b) Wind rose at the height of $80 \mathrm{~m}$. 


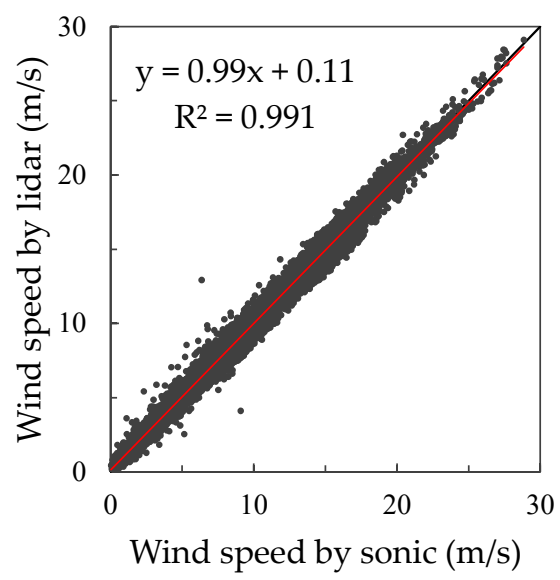

Figure 4. Comparison of $10 \mathrm{~min}$ averaged wind speeds observed by Lidar and Sonic at the height of $80 \mathrm{~m}$.

\section{The Effect of Nudging Scheme, Land-Use and Sea Surface Temperature on the Wind Prediction}

The numerical simulation results are analyzed with respect to different nudging in Section 3.1, land use in Section 3, and sea surface temperature settings in Section 3.3. The simulated wind speed and wind direction are compared with measurement and the effect of each factor is clarified.

\subsection{The Effect of Nudging Scheme}

Nudging is a method of keeping simulations close to analyses and/or observations over the course of integration as shown in Equation (3) [8].

$$
\frac{\partial \theta}{\partial t}=F(\theta)+G_{\theta}\left(\hat{\theta_{0}}-\theta\right)
$$

where $\theta$ is the prediction variable, $F(\theta)$ represents the normal tendency terms due to physics, $G_{\theta}$ is the time-scale controlling the nudging strength and $\hat{\theta_{0}}$ is the time- and space-interpolated analysis field value towards which the nudging relaxes the solution. In this study, $G_{\theta}$ is set as $3.0 \times 10^{-4}$ as a default value and grid nudging is used.

In order to investigate the nudging effect below the planetary boundary layer, observation data is obtained from the Tateno Areological Observatory located at $36^{\circ} 03^{\prime} 30^{\prime \prime} \mathrm{N}, 140^{\circ} 07^{\prime} 30^{\prime \prime}$ E in the world geodetic system, which is the nearest observatory from the Choshi site. The GPS Sonde observation is performed twice a day at 9:00JST and 21:00JST which corresponds to 0:00UTC and 12:00UTC. Monthly average data is used because one-day data has uncertainty.

The effect of nudging on the wind profile is investigated. Table 3 shows the simulation cases. Case1.1 keeps the nudging option on in all layers, Case 1.2 keeps the nudging option on only above the planetary boundary layer (PBL), and Case 1.3 keeps the nudging option on in domain 1 and off in domain 2 and 3 below the PBL. Figure 5 shows the simulated and observed monthly average wind speed below $1500 \mathrm{~m}$ in August when the diurnal variation is the largest in a year. The significant diurnal variation is recognized at 9:00 JST and 21:00 JST (0:00 UTC and 12:00 UTC). The predicted wind profiles in Case 1.1 underestimate the diurnal variation since the local wind climate is suppressed by the nudging, those in Case 1.2 match with the observation at 9:00 JST (0:00 UTC) and on 21:00 JST (12:00 UTC), which reproduce the diurnal variation. It indicates that the nudging above the PBL reproduces the local phenomena with less phase error. Case 1.3 shows the best agreement with observation data. The bias of annual wind speed at hub height is $0.31 \mathrm{~m} / \mathrm{s}$ in Case 1.2 and Case 1.3, while RMSE reduces from 2.74 in Case 1.2 to 2.56 in Case 1.3. As a conclusion, the nudging only used in the outer domain (Case 1.3) suppresses the phase error and reproduces the local wind. 
Table 3. Cases used to investigate the effect of nudging height on the vertical wind profile.

\begin{tabular}{clccc}
\hline \multirow{2}{*}{ Case } & & \multicolumn{3}{c}{ Domain } \\
\cline { 3 - 5 } & & $\mathbf{1}$ & $\mathbf{2}$ & $\mathbf{3}$ \\
\hline \multirow{2}{*}{ Case 1.1 } & Above PBL & $\bigcirc$ & $\bigcirc$ & $\bigcirc$ \\
& Below PBL & $\bigcirc$ & $\bigcirc$ & $\bigcirc$ \\
\hline \multirow{2}{*}{ Case 1.2 } & Above PBL & $\bigcirc$ & $\bigcirc$ & $\bigcirc$ \\
& Below PBL & $\times$ & $\times$ & $\times$ \\
\multirow{2}{*}{ Case 1.3 } & Above PBL & $\bigcirc$ & $\bigcirc$ & $\bigcirc$ \\
& Below PBL & $\bigcirc$ & $\times$ & $\times$ \\
\hline
\end{tabular}

$O$ indicates that the nudging option is on and $\times$ is off.

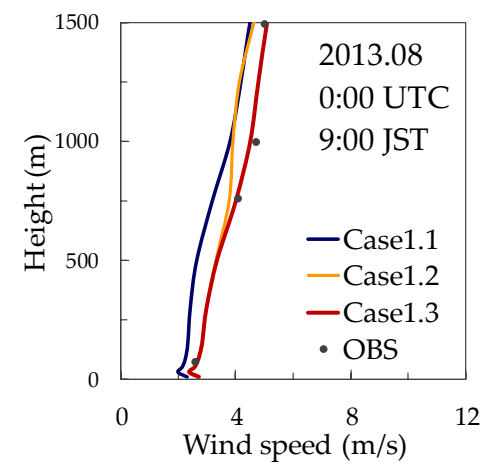

(a)

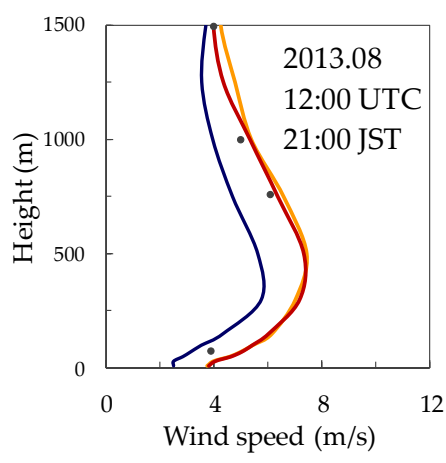

(b)

Figure 5. Effect of nudging height on the monthly average wind speed at Tateno: (a) 0:00 UTC (9:00 JST) in August 2013 (b) 12:00 UTC (21:00 JST) in August 2013.

Finally, the nudging effect on the vertical wind profile in the Choshi site is investigated and shown in Figure 6. The data coverage of the Doppler lidar is $76 \%$ in August. In Case 1.1, the predicted wind profile underestimates the observation since the southerly wind over $10 \mathrm{~m} / \mathrm{s}$ is suppressed. The predicted wind profile in Case 1.2 is improved and in Case 1.3 matches well with the observation. The RMSE in Case 1.3 reduces to $2.56 \mathrm{~m} / \mathrm{s}$ at the height of $80 \mathrm{~m}$.

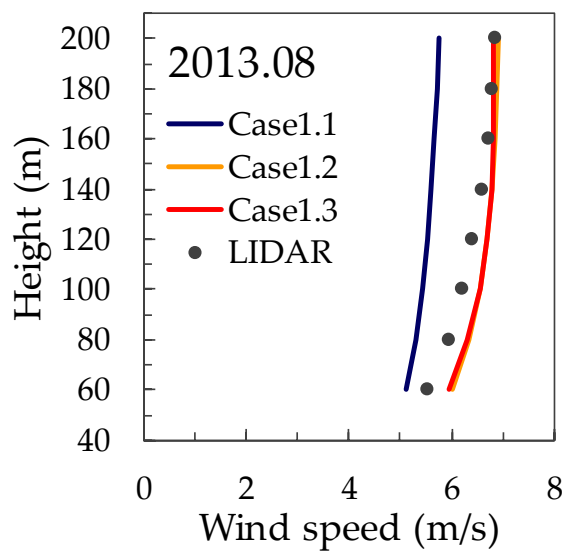

Figure 6. Effect of nudging height on the monthly average wind speed at the Choshi site.in August 2013.

\subsection{The Effect of Land-Use}

The digital elevation data with $50 \mathrm{~m}$ resolution is provided by the Geospatial Information Authority of Japan (GSI) [28] and land-use data with $100 \mathrm{~m}$ resolution is provided by the National Land Information Division (NLID) [29], which are used in this study instead of the standard USGS data. With $100 \mathrm{~m}$ resolution land-use data, the one mesoscale grid of $2 \mathrm{~km}$ has $400(20 \times 20)$ land-use 
data grids. In this case, the nearest neighbor method implemented in the WRF does not extract the representative land-use category, especially in the complex land-use area as shown in Figure 7. The land-use datasets are then created from higher-resolution land- use data by using a maximum area sampling scheme according to the horizontal resolution of the mesoscale model. In order to convert the land-use category of NLID to that of the USGS, the lookup table between the NLID and USGS proposed by Yoshie et al. [30] is used. Figure 8 presents the land-use map of the USGS and NLID on a large and small scale. The reproducibility of the urban area is significantly improved and the shrubland is transferred into the croplands. In Figure $8 \mathrm{~d}$, it is clearly found that the reproducibility of the Tone River is improved.

In this study, the effect of land-use on the wind profile is investigated as shown in Table 4. Case 2.1 and Case 2.2 use the USGS and NLID, respectively. Both cases use Case 1.3 as nudging and OSTIA data as SST as explained in Section 3.3. Figure 9 shows the vertical profile of the monthly average wind speed in December 2013. Data coverage of the Doppler lidar is $91 \%$ in December. The overestimation of wind speed is solved by using land-use data by the NLID because the terrain roughness increases with the high reproducibility of the urban area. The relative bias of monthly average wind speed at the hub height of $80 \mathrm{~m}$ decreases from $5.6 \%$ to $4.2 \%$ by the improvement of land-use data.

Table 4. Cases used to investigate the effect of land-use.

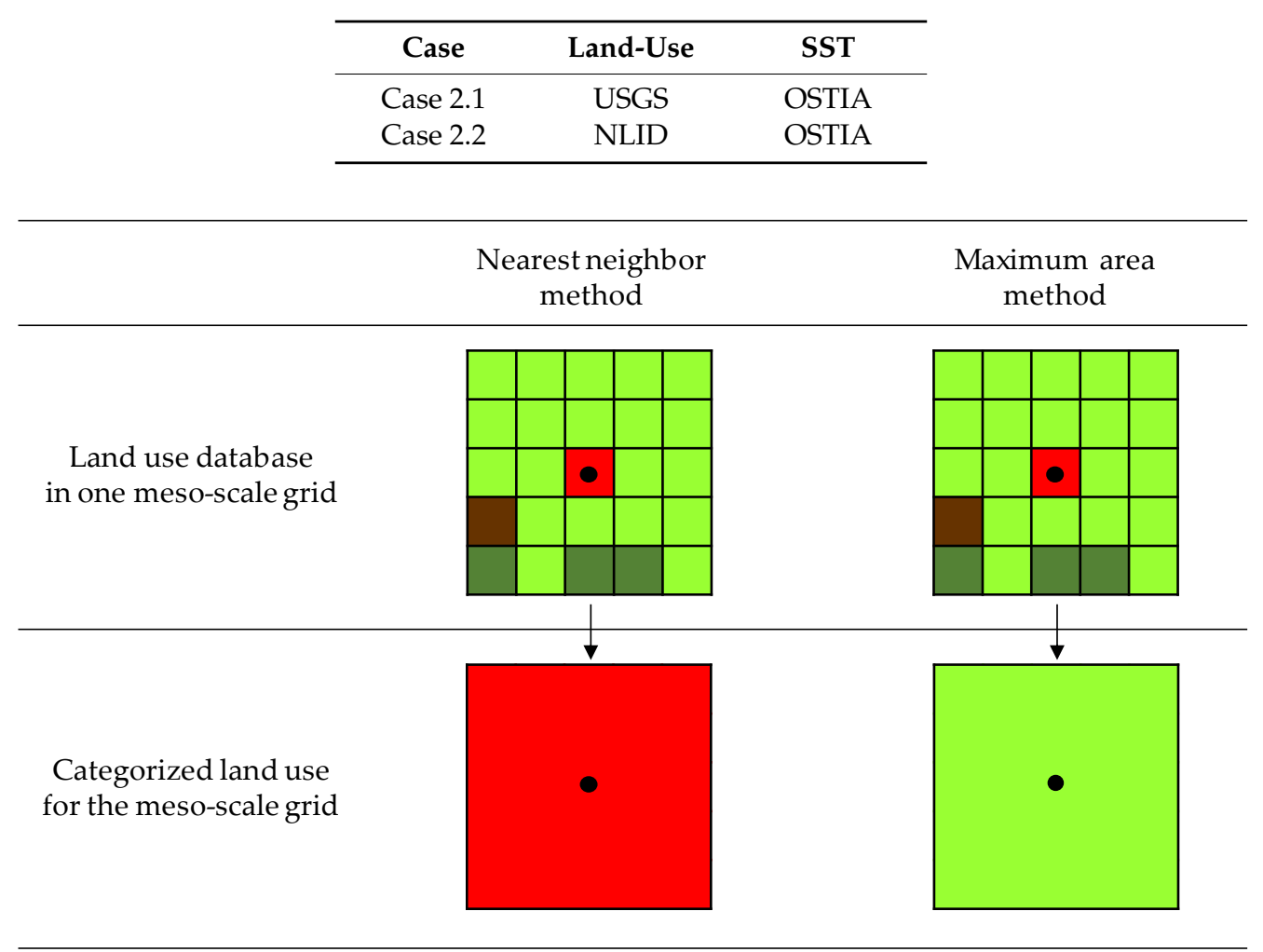

Figure 7. Comparison of each interpolation method for changing land-use datasets to mesoscale grids. 


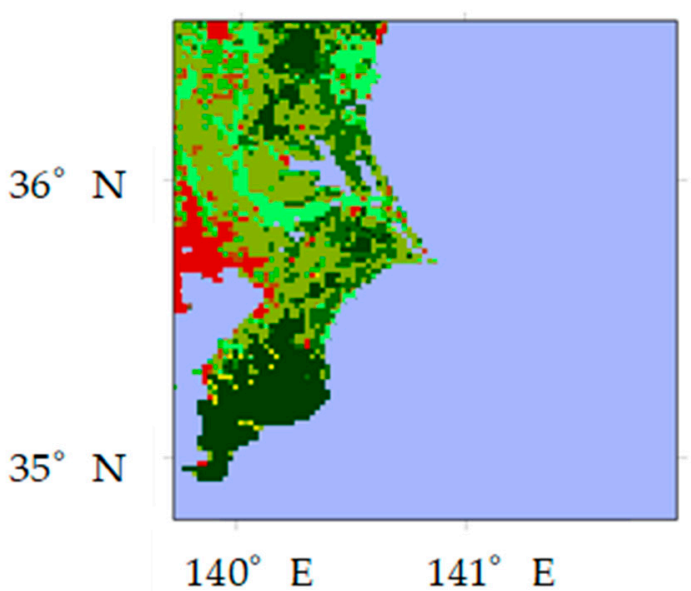

(a)

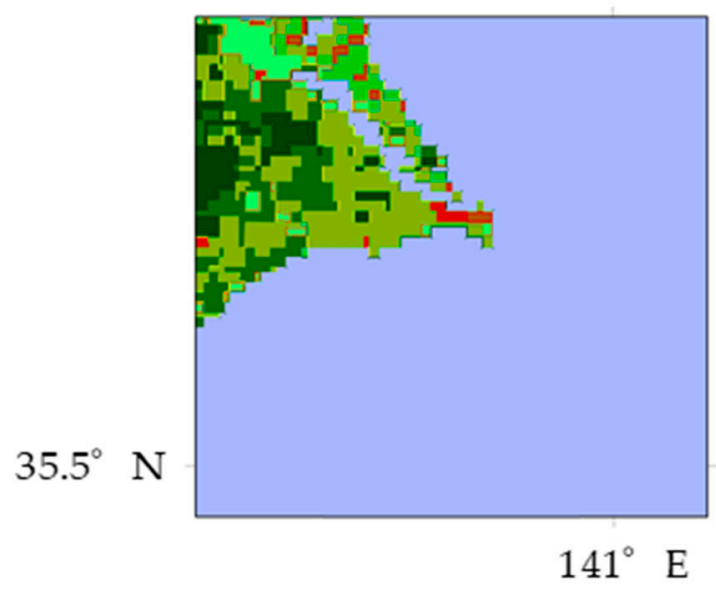

(c)

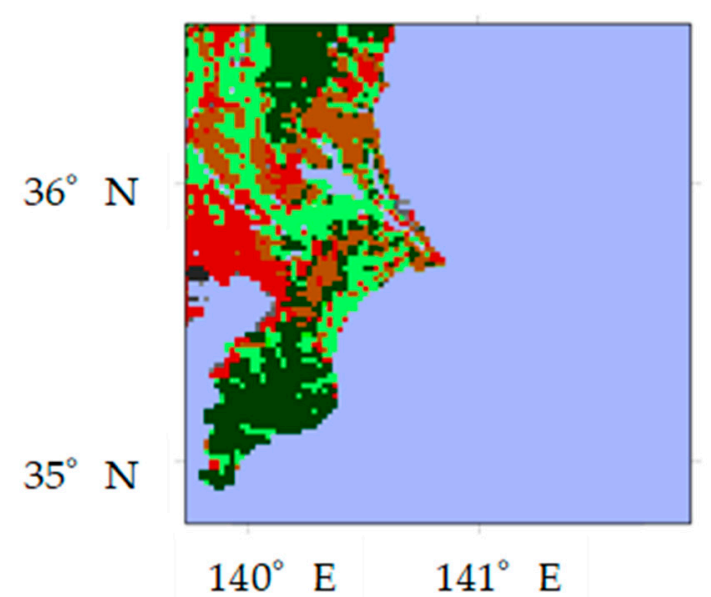

(b)

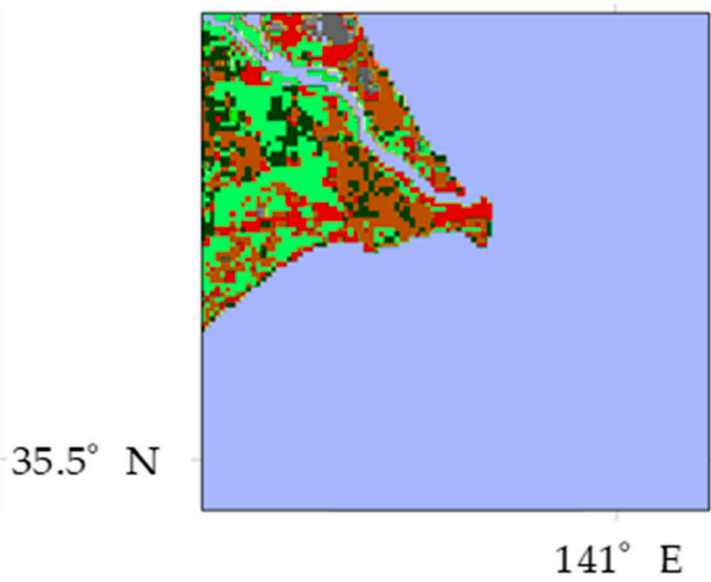

(d)
- Urban
Shrub land
Irrigated cropland
Savanna
Forest
Glass land
Dryland cropland

Figure 8. The land-use data sets applied in this study in the innermost domain: the wide-area map of (a) USGS (b) NLID and the detailed map of (c) USCS (d) NLID.

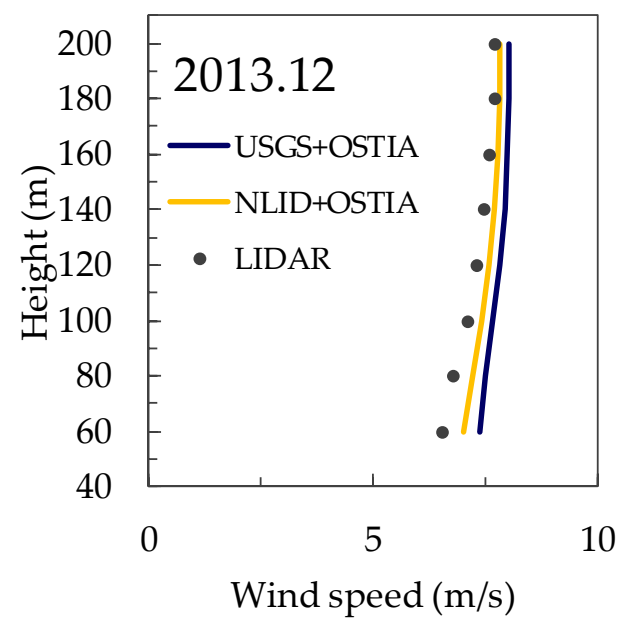

Figure 9. Effect of land-use data on the monthly average wind speed at the Choshi site in December 2013. 


\subsection{The Effect of Sea Surface Temperature}

Sea surface temperature, OSTIA, is used instead of the FNL data provided by the National Centers for Environmental Prediction. OSTIA is a high-resolution analysis of the current SST for the global ocean. The resolution of OSTIA is about 0.05 degrees and thus about $6 \mathrm{~km}$. Figure 10 shows the distribution of SST reproduced by FNL and OSTIA. OSTIA data reproduces the berthing of the Kuroshio current to the Peninsula and the inflow of the Oyashio current, while FNL data does not show the temperature variance in this detail. Figure 11 presents the time series of sea surface temperature by each database and observation data from 1st February 2013 to 31th January 2014 obtained at Hasaki Oceanographical Research Station located $18 \mathrm{~km}$ from Choshi. The figure indicates that FNL overestimates the sea surface temperature for all seasons, while OSTAI shows better agreement with observation. However, OSTIA also shows the maximum error of five Kelvin in the winter season since the Tone River flows in this region and lowers the sea surface temperature.

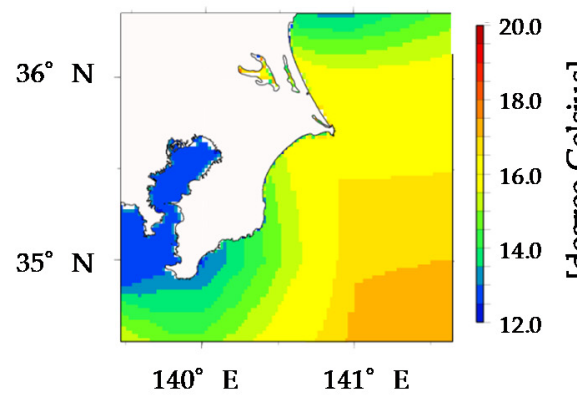

(a)

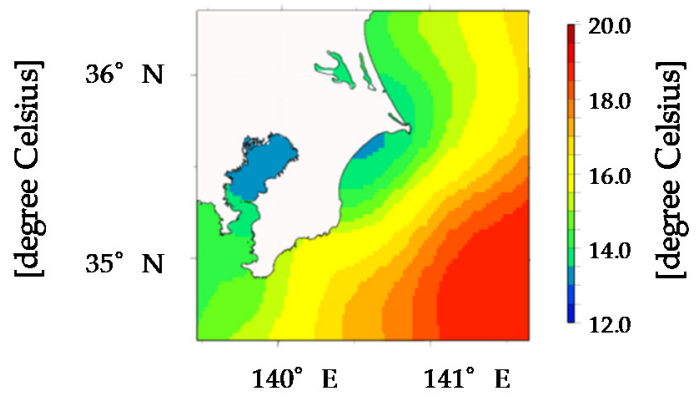

(b)

Figure 10. Sea surface temperature distribution on 01/02/2013 (a) FNL (b) OSTIA.

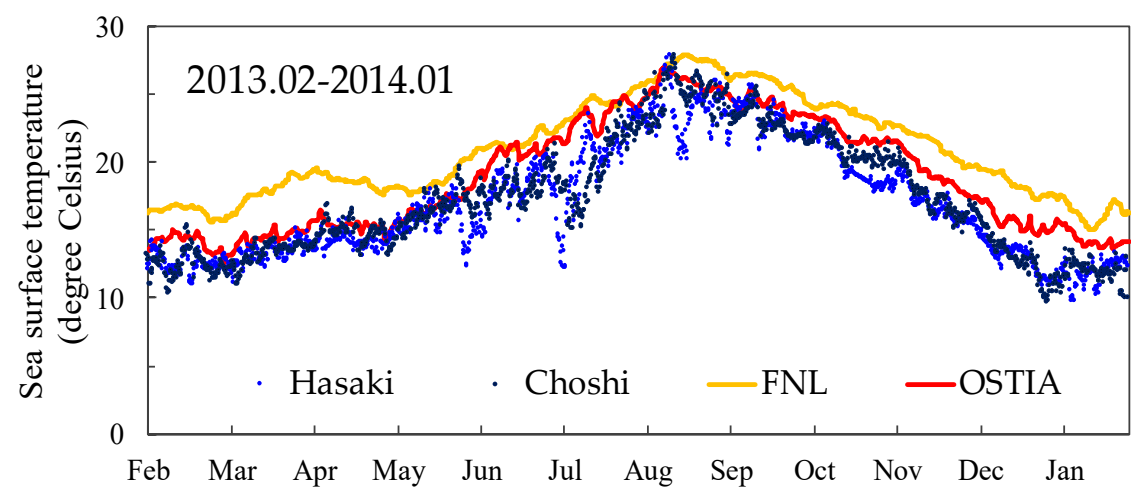

Figure 11. Time series of sea surface temperature by FNL, OSTIA, and observations at Choshi and Hasaki.

In this study, the Cressman function [31] is used for the correction of OSTIA data by the observed sea surface temperature as shown in Equation (4).

$$
W_{i j}=\max \left[0, \frac{R^{2}-d_{i, j}^{2}}{R^{2}+d_{i, j}^{2}}\right]
$$

where $W_{i j}$ is a weight function, $R$ is the influence radius, $d_{i, j}$ is the distance between the observation site $i$ and the mesh point $j$. The influence radius is identified by Equation (5).

$$
\Delta T_{\text {hasaki }}=W_{i . j} \bullet \Delta T_{\text {choshi }}
$$


Here, $\Delta T_{\text {choshi }}$ and $\Delta T_{\text {hasaki }}$ is the difference in sea surface temperature between OSTIA and observations at Choshi and Hasaki. The influence radius is estimated at $226 \mathrm{~km}$, which is much longer than the distance between these two sites. It indicates that the sea surface temperature pattern is very similar between Choshi and Hasaki. The variation characteristic may be different between nearshore and offshore due to the water depth difference. It needs to be verified whether the correction with the nearshore sea surface temperature can be adapted to the offshore sea surface temperature. The correlation factor between the observation data and OSTIA data with different water depths are shown in Figure 12b. The correlation factors are above 0.9 for all water depths. Therefore, the sea surface temperature database is corrected by using the Cressman function. The time resolution of the correction matches the input data of $6 \mathrm{~h}$.

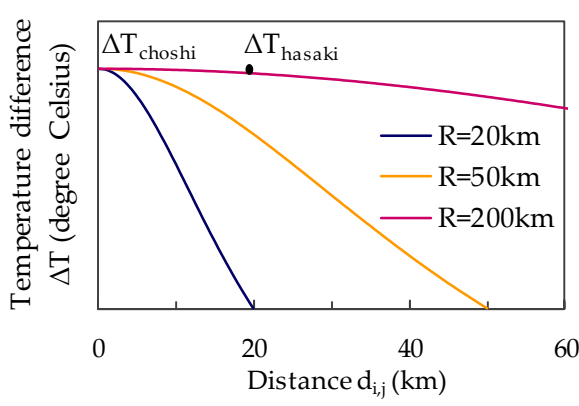

(a)

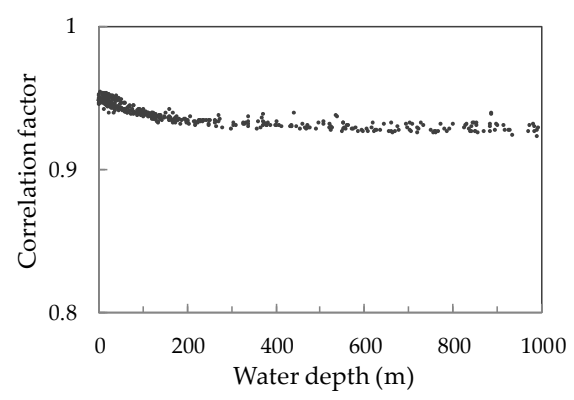

(b)

Figure 12. (a) Variation of sea surface temperature differences with the influence radii in the Cressman function. (b) Distribution of correlation coefficients between OSTIA and observations at Choshi.

The effect of SST on offshore wind speed is investigated as shown in Table 5. Case 3.1 uses FNL and Case 3.2 uses OSTIA corrected by Choshi observation data. Figure 13 shows the vertical profiles of the monthly average wind speed. The bias correction of SST suppresses the convection and improves the overestimation of wind speed. As a result, the relative error in monthly average wind speed decreases from $6.3 \%$ to $2.2 \%$ at the hub height of $80 \mathrm{~m}$.

Table 5. Cases used to investigate the effect of sea surface temperature.

\begin{tabular}{cccc}
\hline Case & Land-Use & $\begin{array}{c}\text { Sea Surface } \\
\text { Temperature }\end{array}$ & Onsite Observation Data \\
\hline Case 3.1 & NLID & FNL & Without Choshi observation data \\
Case 3.2 & NLID & OSTIA & With Choshi observation data \\
\hline
\end{tabular}

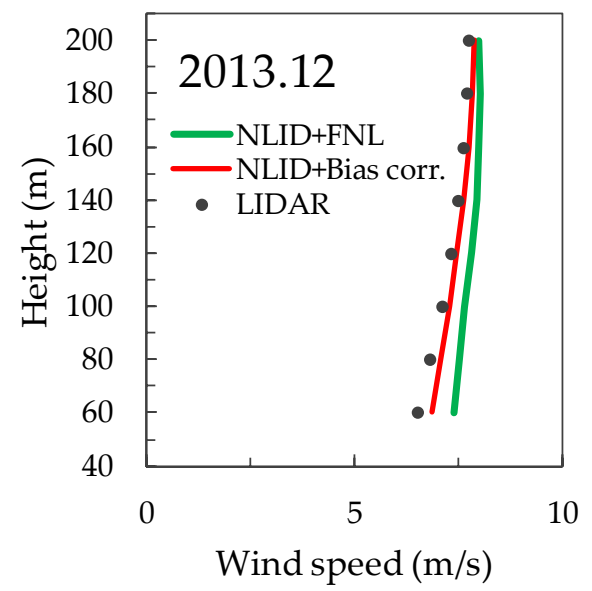

Figure 13. Effect of sea surface temperature on the monthly average wind speed at the Choshi site in December 2013. 


\subsection{Evaluation of Predicted Annual and Seasonal Average Wind Speed}

The effect of high-resolution land-use data and bias-corrected SST data on the annual average wind speed is quantitatively evaluated by two cases as shown in Table 6 .

Figure 14a,b show the frequency distributions of wind speed and wind rose at the hub height. Here, the measured wind speed for all directions are used, which is different from Figure $3 a, b$. The predicted wind speed using NLID and bias-corrected SST shows better accuracy in the low and high wind speed region since the terrain roughness length increases by using the high-resolution land data and the convection is suppressed by using the bias-corrected SST data.

Figure 14c expresses the vertical profiles of annual average wind speed. The high-resolution land data and the bias-corrected SST data significantly improve the predicted annual average wind speed at the low elevation. The predicted annual average wind speed at the height of $200 \mathrm{~m}$ is unaffected by the land-use and sea surface temperature and the relative error for each case is less than $1 \%$. Figure $14 \mathrm{~d}$ shows the annual average wind speed in each wind direction at the hub height. The predicted annual average wind speed in the north direction is improved by reproducing the Choshi city with high-resolution land-use data. The overestimation of wind speed in the south-west wind direction is also improved.

In comparison between default data used in Case 4.1 and updated data in Case 4.2, the relative error of annual average wind speed at the hub height decreases from $7.3 \%$ to $2.2 \%$ and the correlation factor of wind speed improves from 0.80 to 0.84 at the hub height of $80 \mathrm{~m}$. Table 7 shows the relative error for each combination of land-use data and SST data. The $1 \%$ relative error is reduced by the high-resolution land-use data and $4.1 \%$ is reduced by using the bias-corrected SST data. The improvement of prediction accuracy in wind speed is due to the terrain roughness increase and the sea surface temperature decrease which suppresses the convection in the winter season.

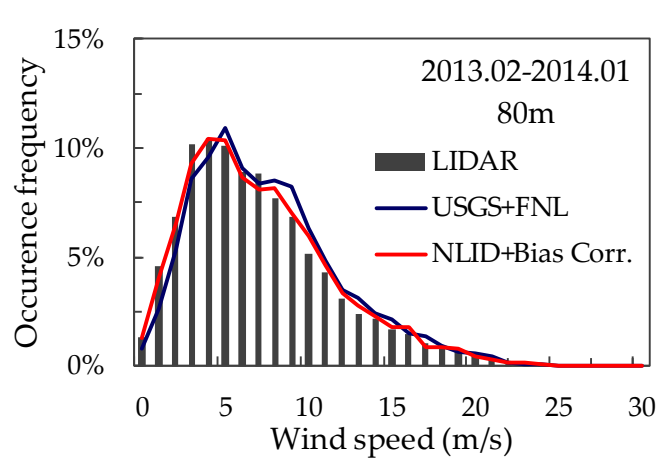

(a)

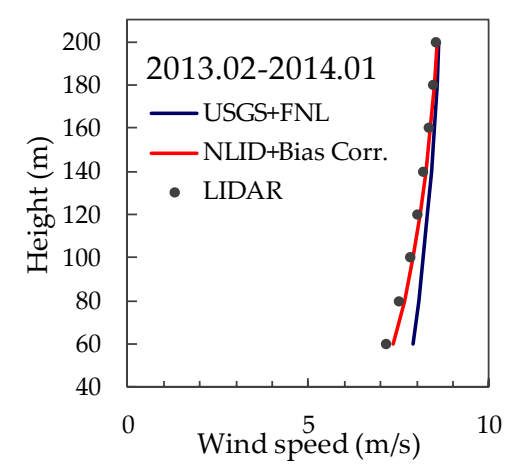

(c)

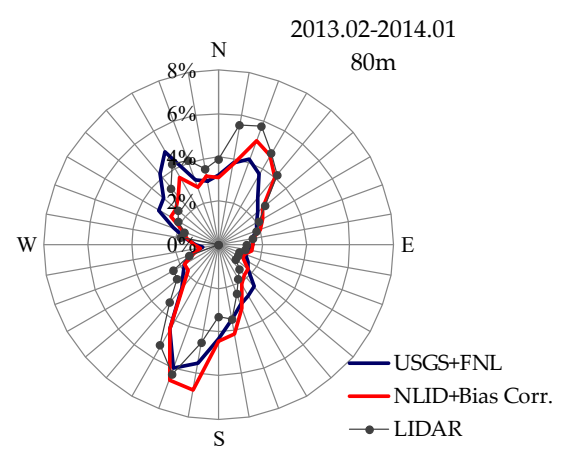

(b)

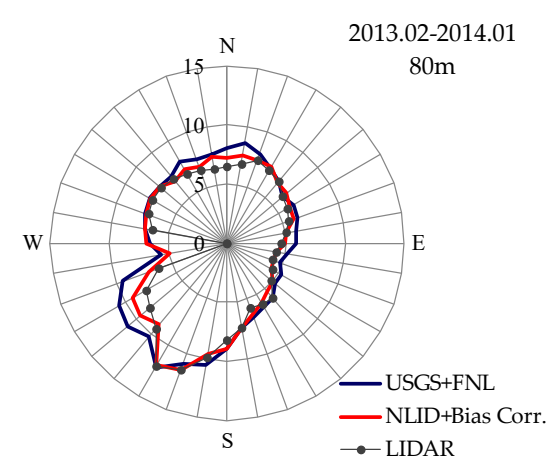

(d)

Figure 14. Effect of land-use and bias-corrected SST on the offshore wind. (a) Frequency distributions of wind speed at the hub height; (b) Wind rose; (c) Vertical profiles of annual average wind speed; (d) Directional annual average wind speeds. 
Table 6. Cases used to evaluate the predicted annual average wind speed.

\begin{tabular}{ccccc}
\hline Case & Land-Use & $\begin{array}{c}\text { Sea Surface } \\
\text { Temperature }\end{array}$ & Relative Error & Correction Factor \\
\hline Case 4.1 & USGS & FNL & $7.3 \%$ & 0.80 \\
Case 4.2 & NLID & Bias corrected OSTIA & $2.2 \%$ & 0.84 \\
\hline
\end{tabular}

Table 7. Relative error for each case.

\begin{tabular}{|c|c|c|c|c|c|c|}
\hline \multicolumn{2}{|c|}{ Land-use Data } & \multicolumn{3}{|c|}{ Sea Surface Temperature } & \multirow{2}{*}{ Relative Error } & \multirow{2}{*}{ Correlation } \\
\hline USGS & NLID & FNL & OSTIA & Bias Correction & & \\
\hline \multirow[t]{2}{*}{$\bigcirc$} & & $\square$ & & & $7.3 \%$ & 0.80 \\
\hline & - & $\square$ & & & $6.3 \%$ & \\
\hline \multirow[t]{3}{*}{$\bigcirc$} & & & $\boldsymbol{\square}$ & & $5.6 \%$ & \\
\hline & $\bullet$ & & $\boldsymbol{\square}$ & & $4.2 \%$ & \\
\hline & - & & - & $\Delta$ & $2.2 \%$ & 0.84 \\
\hline
\end{tabular}

$\bigcirc$ and $\bullet$ express the default land-use data and the land-use data used in this study, respectively. $\square$ and $\square$ represent the default SST data and SST data used in this study. $\mathbf{\Delta}$ denotes the OSTIA data with the bias-correction.

Figure 15 presents the monthly average wind speed at the hub height. The predicted monthly average wind speed in Case 4.1 shows a large error in the winter season, while the predicted monthly average wind speed in Case 4.2 using the bias-corrected SST, the relative error of monthly average wind speed reduces from $15.8 \%$ to $4.1 \%$ in December.

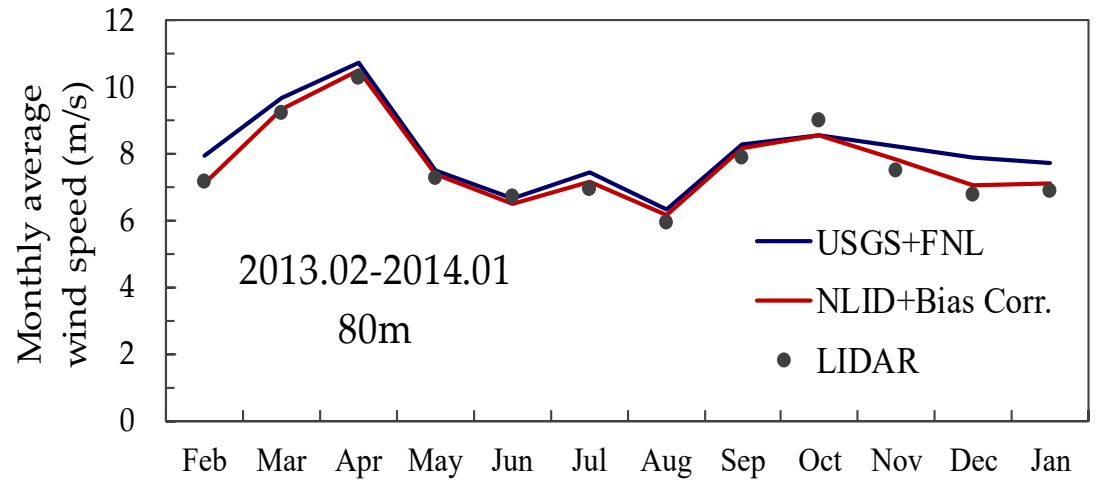

Figure 15. Monthly averaged wind speed at the hub height of $80 \mathrm{~m}$.

The seasonal variation of atmospheric stability is investigated and categorized with the five levels proposed by Sathe et al. [32] as shown in Table 8. The observation of Monin-Obukhov length is evaluated by using the flux calculated from the ultrasonic anemometer installed at the hub height of $80 \mathrm{~m}$. Figure 16 presents the monthly frequency of atmospheric stability of observation, Case 5.1 and Case 5.2. The predicted occurrence frequency of unstable conditions in Case 5.1 is significantly overestimated by using the USGS and FNL as shown in Figure 16b, while those using the NLID with the bias-corrected SST in Case 5.2 becomes close to the observation as shown in Figure 16c. Figure 17 shows the diurnal variation of hourly average wind speed at the hub height of $80 \mathrm{~m}$. The underestimation of wind speed by using the USGS and FNL in the night time is significantly improved by using the NLID data and the bias-corrected SST. 
Table 8. Classification of atmospheric stability according to Monin-Obukhov length intervals.

\begin{tabular}{cc}
\hline Atmospheric Stability Category & Monin-Obukhov Length \\
\hline Very stable & $10<\mathrm{L}<50$ \\
Stable & $50<\mathrm{L}<200$ \\
Neutral & $|\mathrm{L}|>200$ \\
Unstable & $-200<\mathrm{L}<-100$ \\
Very unstable & $-100<\mathrm{L}<-50$ \\
\hline
\end{tabular}

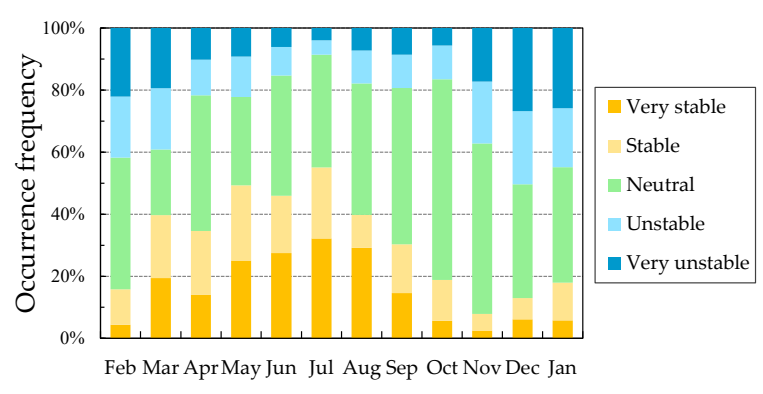

(a)

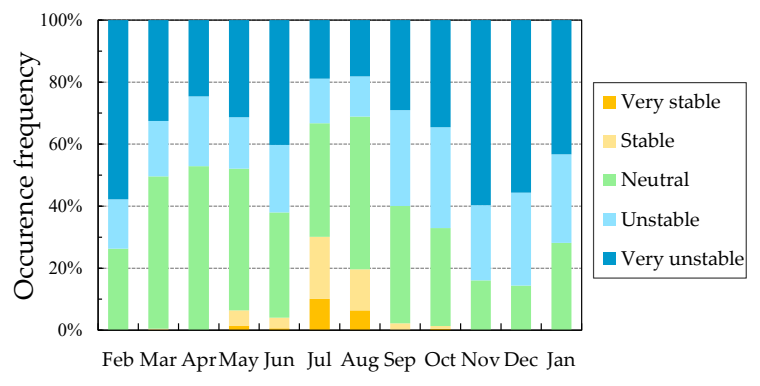

(b)

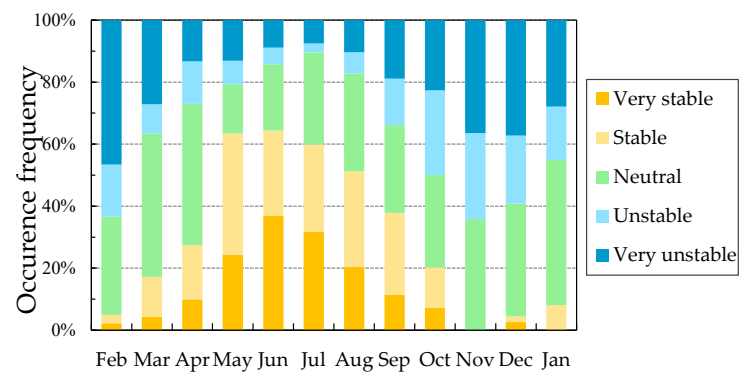

(c)

Figure 16. Seasonal variation of atmospheric stability: (a) Observation, (b) USGS+FNL (Case4.1) and (c) NLID+BIAS Corrected SST (Case4.2).

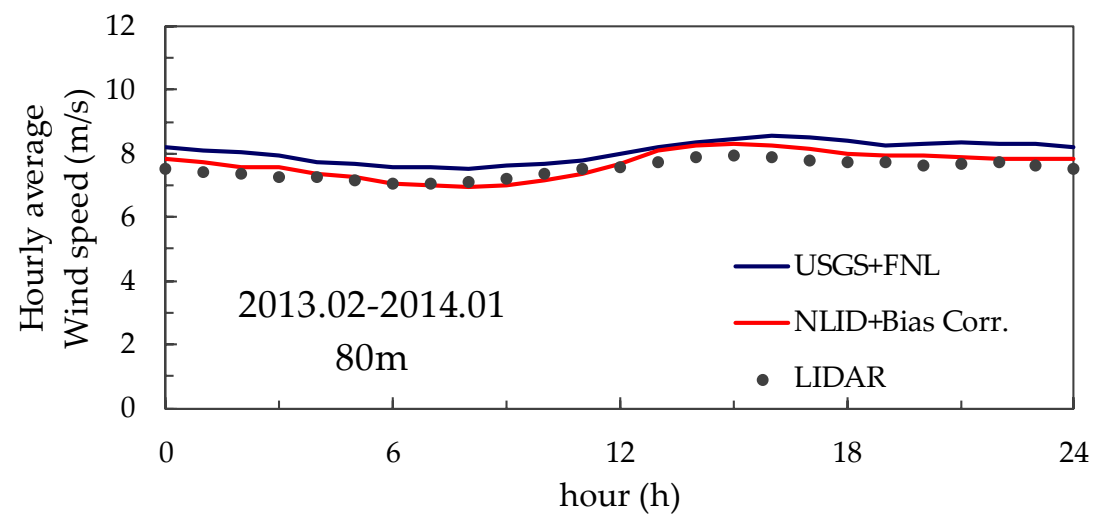

Figure 17. Diurnal variation of hourly averaged wind speed at the hub height of $80 \mathrm{~m}$.

\section{Conclusions}

In this study, the annual wind speed and direction are predicted by the mesoscale model WRF in a coastal region considering the nudging scheme, land-use, and sea surface temperature data sets. The predicted wind profile is compared with the observation, and the following conclusions are obtained. 
1. When the nudging is applied to full levels in the outer domain and to the levels above the planetary boundary layer in the domains, the local wind is reproduced and the phase error is suppressed at the same time.

2. The land-use datasets are created from a higher-resolution land-use data by using the maximum area sampling scheme according to the horizontal resolution of the mesoscale model. The high-resolution land-use data improves the overestimation of the northerly wind from the Choshi area.

3. The bias-correction method for the sea surface temperature is proposed by using the onsite observation data. The bias-corrected sea surface temperature suppresses the convection in the winter season and improves the overestimation of annual average wind speed in the south-western direction.

4. The relative error of annual average wind speed at the hub height reduces from $7.3 \%$ to $2.2 \%$ and the correlation factor of wind speed improves from 0.80 to 0.84 by using the high-resolution land-use data and bias-corrected sea surface temperature in the coastal region. The $1 \%$ relative error is reduced by using high-resolution land-use data and $4.1 \%$ is reduced by using the bias-corrected SST data.

Author Contributions: conceptualization, T.I. and M.F.; methodology, T.I.; software, M.F.; validation, M.F.; investigation, M.F.; data curation, M.F.; writing—original draft preparation, Y.K.; writing—review and editing, Y.K.; visualization, Y.K.; supervision, T.I.; project administration, T.I.; funding acquisition, T.I. All authors have read and agreed to the published version of the manuscript.

Acknowledgments: The measurement data was obtained from New Energy and Industrial Technology Development Organization (NEDO), Japan. Port and Airport Research Institute provided the sea temperature data. The authors wish to express their deepest gratitude to the concerned parties for thesis assistance during this study.

Conflicts of Interest: The authors declare no conflict of interest.

\section{References}

1. FINO1-Research Platform in the North and Baltic Seas No.1. Available online: https://www.fino1.de/en/ about-fino1.html (accessed on 4 April 2020).

2. FINO2-Reseach Platform in the Baltic Sea. Available online: https://www.fino2.de/en/ (accessed on 4 April 2020).

3. FINO3-Reseach Platform in the North Sea and the Baltic No.3. Available online: https://www.fino3.de/en/ (accessed on 4 April 2020).

4. Meteomast IJmuiden. Available online: https://www.windopzee.net/en/locations/meteomast-ijmuiden-mmij/ (accessed on 4 April 2020).

5. New Energy and Industrial Technology Development Organization (NEDO), Offshore Observation Facility Open Data. Available online: http://www.nedo.go.jp/fuusha/public/index.html (accessed on 4 April 2020).

6. Yamaguchi, A.; Ishihara, T. A new motion compensation algorithm of floating lidar system for the assessment of turbulence intensity. J. Phys. Conf. Ser. 2016, 753, 072034. [CrossRef]

7. Kelberlau, F.; Neshaug, V.; Lonseth, L.; Bracchi, T.; Mann, J. Taking the motion out of floating lidar: Turbulence intensity estimates with a continuous-wave wind lidar. Remote Sens. 2020, 12, 898. [CrossRef]

8. Skamarock, W.; Klemp, J.; Dudhia, J.; Gill, D.; Barker, D.; Duda, M.; Huang, X.; Wang, W.; Powers, J. A Description of the Advanced Research WRF Version 3; (No. NCAR/TN-475+ STR); University Corporation for Atmospheric Research: Boulder, Colorado, USA, 2008. [CrossRef]

9. Berge, E.; Byrkjedal, Ø.; Ydersbond, O.; Kindler, D. Modeling of offshore wind resources. Comparison of meso-scale model and measurements from FINO-1 and North Sea oil rigs. In Proceedings of the European Wind Energy Conference 2009, Marseille, France, 16-19 March 2009.

10. Hahmann, A.N.; Vincent, C.L.; Pena, A.; Lange, J.; Hasager, C.B. Wind climate estimation using WRF model output: Method and model sensitivities over the sea. Int. J. Climatol. 2015, 35, 3422-3439. [CrossRef]

11. Fukushima, M.; Yamaguchi, A.; Ishihara, T. Offshore wind speed prediction by using mesoscale model. In Proceedings of the Grand Renewable Energy 2014, Yokohama, Japan, 27 July-1 August 2014. 
12. Ishihara, T.; Yamaguchi, A.; Goit, J.; Tanemoto, J. Validation of numerical weather simulation by using 3D scanning lidar. J. Wind Eng. 2017, 42, 87-88. (In Japanese) [CrossRef]

13. Lopez-Espinoza, E.D.; Zavala-Hidalgo, J.; Gomez-Ramos, O. Weather forecast sensitivity to changes in urban land covers using the WRF Model for central Mexico. Atmósfera 2012, 25, 127-154.

14. Cheng, F.Y.; Hsu, Y.C.; Lin, P.L.; Lin, T.H. Investigation of the effects of different land use and land cover patterns on mesoscale meteorological simulations in the Taiwan area. J. Appl. Meteor. Climatol. 2013, 52, 570-587. [CrossRef]

15. Li, D.; Bou-Zeid, E.; Baeck, M.; Jessup, S.; Smith, J. Modeling land surface processes and heavy rainfall in urban environments: Sensitivity to urban surface representations. J. Hydrometeor. 2013, 14, 1098-1118. [CrossRef]

16. Kamal, S.; Huang, H.-P.; Myint, S.W. The influence of urbanization on the climate of the Las Vegas metropolitan area: A numerical study. J. Appl. Meteor. Climatol. 2015, 54, 2157-2177. [CrossRef]

17. Mallard, M.S.; Spero, T.L.; Taylor, S.M. Examining WRF's sensitivity to contemporary land-use datasets across the contiguous United States Using Dynamical Downscaling. J. Appl. Meteor. Climatol. 2018, 57, 2561-2583. [CrossRef]

18. Yoshie, R.; Mirura, S. Preparation of standard wind data for assessment of pedestrian wind environment using WRF. J. Wind Eng. 2014, 39, 154-159. (In Japanese) [CrossRef]

19. Shimada, S.; Osawa, T.; Kogaki, T.; Steinfeld, G.; Heinemann, D. Effects of sea surface temperature accuracy on offshore wind resource assessment using a mesoscale model. Wind Energy 2015, 18, 1839-1854. [CrossRef]

20. Donlon, C.J.; Martin, M.; Stark, J.; Roberts-Jones, J.; Fiedler, E.; Wimmer, W. The operational sea surface temperature and sea ice analysis (OSTIA). Remote Sens. Environ. 2012, 116, 140-148. [CrossRef]

21. NOAA Earth System Research Laboratory, NCEP Reanalysis Data Provided by the NOAA/OAR/ESRL PSD, Boulder, Colorado, USA. Available online: http://www.esrl.noaa.gov/psd/ (accessed on 4 April 2020).

22. Witha, B.; Hahmann, A.; Sile, T.; Dorenkamper, M.; Ezber, Y.; Garcia-Bustamante, E.; Gonzalez-Rouco, J.F.; Leroy, G.; Navarro, J. WRF model sensitivity studies and specifications for the NEWA mesoscale wind atlas production runs. New Eur. Wind Atlas Deliv. 2019, 4.

23. Stauffer, D.R.; Seaman, N.L.; Binkowski, F.S. Use of Four-Dimensional Data Assimilation in a Limited-Area Mesoscale Model Part II: Effects of Data Assimilation within the Planetary Boundary Layer. Mon. Wea. Rev. 1991, 119, 734-754. [CrossRef]

24. Stauffer, D.R.; Seaman, N.L.; Binkowski, F.S. Use of Four-Dimensional Data Assimilation in a Limited-Area Mesoscale Model Part I: Experiments with Synoptic-Scale Data. Mon. Wea. Rev. 1990, 118, 1250-1277. [CrossRef]

25. Vincent, C.L.; Hahmann, A. The impact of grid and spectral nudging on the variance of the near-surface wind speed. J. Appl. Meteor. Clim. 2015, 54, 1021-1038. [CrossRef]

26. Misaki, T.; Ohsawa, T.; Konagaya, M.; Shimada, S.; Takeyama, Y.; Nakamura, S. Accuracy comparison of coastal wind speeds between WRF simulations using different input datasets in Japan. Energies 2019, 12. [CrossRef]

27. U.S. Geological Survey. Land Use Land Cover Modeling. Available online: https://www.usgs.gov/landresources/eros/lulc/data-tools (accessed on 4 April 2020).

28. Geospatial Information Authority of Japan, GSI Web Site. Available online: https://www.gsi.go.jp/ENGLISH/ page_e30233.html (accessed on 4 April 2020).

29. National Spatial Planning and Regional Policy Bureau of Japan, Land Use Tertiary Mesh Data. Available online: http://nlftp.mlit.go.jp/ksj-e/gml/datalist/KsjTmplt-L03-a.html (accessed on 4 April 2020).

30. Yoshie, R.; Miura, S.; Mochizuki, M. Validation of WRF for preparation of standard wind data for assessment of pedestrian wind environment. J. Wind Eng. 2015, 40, 113-122. (In Japanese) [CrossRef]

31. Cressman, G.P. An operational objective analysis system. Mon. Wea. Rev. 1959, 87, 367-374. [CrossRef]

32. Sathe, A.; Grying, S.; Pena, A. Comparison of the atmospheric stability and wind profiles at two wind farm sites over a long marine fetch in the North Sea. Wind Energy 2011, 14, 767-780. [CrossRef]

(C) 2020 by the authors. Licensee MDPI, Basel, Switzerland. This article is an open access article distributed under the terms and conditions of the Creative Commons Attribution (CC BY) license (http://creativecommons.org/licenses/by/4.0/). 